\title{
Study on the Relationship between the Deeps of Coal Seam and the Quantity of $\mathrm{CO}_{2}$ Produced
}

\author{
Jianyou Di ${ }^{1}$, Erxin $\mathrm{Gao}^{2}$, Xianlong $\mathrm{Sun}^{3}$, Qiang Wang ${ }^{4}$, Yuxuan $\mathrm{Xu}^{5}$ \\ China University of Mining and Technology (Beijing) \\ Beijing, China \\ E-mail: xkdjy@126.com¹ Gaoerxin@163.com² sunlong10000@126.com³1196352471@qq.com ${ }^{4}$ xuanat163@163.com ${ }^{5}$
}

\begin{abstract}
Based on the data by Xin-Wen Mining Group CO. LTD of Sun-Cun Coal Mine, the relationship between the geothermal gradient and the depth of mine in Suncun Coal Mine has been developed. According to this and the laboratory experiments, the relationship between the quantity of $\mathrm{CO}_{2}$ and the depth of coal mine has been obtained in this article. The results show that the curve on the period of time on spontaneous combustion of coal and the quantity of $\mathrm{CO}_{2}$ fit cubic polynomial expression in line. Especially when the quantity of $\mathrm{CO}_{2}$ produced exceeds $0.13 \mathrm{~mol} /(\mathrm{Kg} \cdot \mathrm{min})$, the period of time on spontaneous combustion of coal is unchanged. This law should be paid more attention to.
\end{abstract}

Keywords-Spontaneous combustion of coal; The coal mine depth; Carbon dioxide Produced

\section{INTRODUCTION}

Shandong province Xin-Wen Mining Group CO. LTD of Sun-Cun Coal Mine is one of the deepest coal mine in China. It has reached 1,400 meters depth and heat is one of the main problems in this mine. When the depth of coal mine reached $-600 \mathrm{~m}$, the heat injury has become a major disaster and the spontaneous combustion of coal is special serious during mine production. So based on the quantity of $\mathrm{CO}_{2}$ produced by the thirteenth coal seam in Sun-Cun Coal Mine.

The relationship of the quantity of $\mathrm{CO}_{2}$ and the depth of the mine has been studied. This research results will be beneficial to prevent of spontaneous combustion on the coal seam in Sun-Cun Coal Mine.

\section{GenERAL SituATION[1]}

Sun-Cun Coal Mine is in the territory of Xin-Tai City, which is located in the eastern side of Mount Tai in Shandong Province. The mine has been through six layer mining. The production conditions is becoming more and more deteriorating during the depth of coal mine reached $600 \mathrm{~m}$. The physical properties of the coal mine in Sun-Cun Coal Mine is black, dark brown powder and the bulk density is 1.36. The hardness is small and the fracture has stair-step shape. The coal is brittle, fragile and the conductive is weak. The coal seams of bright coal, dull coal and vitrain have been wider intersected. It has band structure and the layer structure. There are occasionally fusain in interlayer. It is the low gaseous mine. Coal dust explosion index was $36.14 \%$ and the coal spontaneous combustion period is 57 days. Original ground temperature is expected to be $40^{\circ} \mathrm{C} \sim$ $41^{\circ} \mathrm{C}$ and the rock pressure is $2518.65 \sim 2863.60 \mathrm{~T} / \mathrm{m}^{2}$.

The average thickness of $13 \#$ coal seam is $0.96 \mathrm{~m}$ and the thickness varies between $0.72 \sim 1.37 \mathrm{~m}$. Its thickness has the trend of thiner from shallow to deep. The 13 \# coal seam has complex structure and it has dirt band 3 to 5 layers. The lithology in dirt band is carbonaceous sandstone. It is hard and the layer is poor. The specific parameters of the 13\# coal seam is in the table 1 .

TABLE I. THE COAL QUALITY INDICATORS IN THE 13\# COAL SEAM

\begin{tabular}{|c|c|c|c|c|c|}
\hline \multirow{2}{*}{ Coal seam } & \multirow{2}{*}{ Thickness (m) } & The number of dirt band & \multirow{2}{*}{ Coal seam Spacing(m) } & \multirow{2}{*}{ Structure } & \multirow{2}{*}{ Stability } \\
\hline & & The thickness of dirt band & & & \\
\hline $13^{\#}$ & $\frac{0.72 \sim 1.37}{0.96}$ & $\frac{3 \sim 5}{0.19 \sim 0.46}$ & $\frac{12.0 \sim 15.0}{13.5}$ & Complicated & Stable \\
\hline
\end{tabular}

TABLE II

THE SEAM FEATURES IN 13\# COAL SEAM

\begin{tabular}{|c|c|c|c|c|c|}
\hline \multirow{2}{*}{ Coal seam } & \multirow{2}{*}{ Thickness (m) } & The number of dirt band & \multirow{2}{*}{ Coal seam Spacing $(\mathrm{m})$} & \multirow{2}{*}{ Structure } & \multirow{2}{*}{ Stability } \\
\hline & & The thickness of dirt band & & & \\
\hline $13^{\#}$ & $\frac{0.72 \sim 1.37}{0.96}$ & $\frac{3 \sim 5}{0.19 \sim 0.46}$ & $\frac{12.0 \sim 15.0}{13.5}$ & Complicated & Stable \\
\hline
\end{tabular}


TABLE III.

THE INDUSTRY ANALYSIS IN 13\# COAL SEAM

\begin{tabular}{|c|c|c|c|c|c|c|c|c|}
\hline \multirow[b]{2}{*}{ Coal seam } & \multicolumn{3}{|c|}{ proximate analysis $(\%)$} & \multicolumn{3}{|c|}{ ignition temperature $\left({ }^{\circ} \mathrm{C}\right)$} & \multirow[b]{2}{*}{$\Delta \mathrm{T}$} & \multirow[b]{2}{*}{$\begin{array}{l}\text { spontaneous combustion } \\
\text { tendency }\end{array}$} \\
\hline & $\begin{array}{c}\text { Moisture content } \\
\mathrm{M}_{\mathrm{ad}}\end{array}$ & $\begin{array}{c}\text { ash content } \\
A_{d}\end{array}$ & $\begin{array}{c}\text { Volatile content } \\
\mathrm{V}_{\mathrm{daf}}\end{array}$ & $\mathrm{T}$ (oxidation) & $\mathrm{T}$ (original) & $\mathrm{T}$ (reduction) & & \\
\hline $\begin{array}{l}\text { The sample in } 13^{\#} \\
\text { coal seam }\end{array}$ & 0.56 & 21.31 & 46.30 & 355 & 359 & 360 & 5 & $\begin{array}{l}\text { Class III Not easy spontaneous } \\
\text { combustion }\end{array}$ \\
\hline
\end{tabular}

III. RESEARCh ON THE RELATIONSHIP BETWEEN THE Depth Of The Mine And The Geothermal Gradient

\section{TABLE IV. GROUND DRILLING TEMPERATURE}

\begin{tabular}{c|c|c|c|c}
\hline \multirow{2}{*}{ Depth $(\mathrm{m})$} & \multicolumn{4}{|c}{ Temperature $\left({ }^{\circ} \mathrm{C}\right)$} \\
\hline & The 1\# hole & The 2\# hole & The 3\# hole & The 4\# hole \\
\hline 20 & 20.0 & 20.9 & & 7.70 \\
\hline 100 & 21.0 & 21.3 & & 17.5 \\
\hline 200 & 23.3 & 24.2 & & 19.1 \\
\hline 300 & 25.6 & 27.7 & & 21.7 \\
\hline 400 & 27.9 & & & 23.7 \\
\hline 500 & 31.1 & 29.8 & & 26.7 \\
\hline 600 & 34.0 & 32.2 & & 29.6 \\
\hline 700 & 36.2 & 37.8 & 29.0 & 31.6 \\
\hline 800 & 38.5 & 36.9 & 35.5 & \\
\hline 900 & 40.8 & & 42.0 & \\
\hline 1000 & 43.5 & & & \\
\hline
\end{tabular}

There are a lot of heat sources to cause the mine temperatures increasing. The underground temperature can be increased from geothermal heat of surrounding rock, large electrical equipment, coal and rock and supporting materials exothermic dissipation and the human body heat. Moreover, surface seasonal climate change is also a significant impact on the underground temperature. The main source that causes high temperature in the Sun-Cun Coal Mine is the geothermal heat and the air compression. The mine is heat conduction type mine, whose main heat source is geothermal. The surrounding rock and coal (rock) exothermic accounted for more than 50\%. With the mining depth increasing, the rate of surrounding rock heat release increases.

Mine exploration drilling was conducted on the ground to measure the geothermal, the drilling test results is listed in Table 4.

Based on the data in the table, the linear relationship between the temperature ( $\mathrm{t}$ ) and the depth (h) has been getten. It is showed as the formula (1):

$$
t=0.02475 h+18.66
$$

The formula shows that the temperature (t) and depth (h) has the feature of linear within certain depth range.

IV. STUDY ON THE RELATIONSHIP BETWEEN THE QUANTITY OF PRODUCED $\mathrm{CO}_{2}$ AND THE TIME DURING ON SPONTANEOUS COMBUSTION OF COAL

Under adiabatic conditions, the coal will be slowly oxidized at normal temperature. So the period of time from self-heating temperature to the critical temperature of accelerate the oxidation can be counted as the shortest coal spontaneous combustion time. According to the thermal oxidation experiments, the critical temperature is determined by the coal samples be accelerated oxidation and the heat release rate of coal samples is determined by the amount of gas productd.

Based on the mathematical optimization model [2], the experimental data of the time during on spontaneous combustion of coal as shown in Table 5.

TABLE V. EXPERIMENTAL DATA ON THE COAL SPONTANEOUS COMBUSTION

\begin{tabular}{|c|c|c|c|c|c|c|c|}
\hline $\mathrm{t}(\mathrm{i})(\mathrm{K})$ & $\mathrm{V}_{\mathrm{O} 2}\left(10^{-6} \mathrm{~mol} / \mathrm{min}\right)$ & $\mathrm{V}_{\mathrm{CO}}\left(10^{-6} \mathrm{~mol} / \mathrm{min}\right)$ & $\mathrm{V}_{\mathrm{CO} 2}\left(10^{-6} \mathrm{~mol} / \mathrm{min}\right)$ & $\mathrm{Q}(\mathrm{J} / \mathrm{Kg} \cdot \mathrm{min})$ & $\mu\left(\mathrm{m}^{3} / \mathrm{Kg}\right)$ & $\mathrm{W}_{\mathrm{P}}(\%)$ & $\tau(\mathrm{d})$ \\
\hline 289 & 0.3376 & 0 & 0.1510 & 5.8641 & 12.4371 & & 0 \\
\hline 322 & 0.3636 & 0 & 0.1374 & 5.6269 & 7.3945 & & 16.0876 \\
\hline 343 & 0.4835 & 0 & 0.1307 & 6.0376 & 4.2240 & & 9.3627 \\
\hline 368 & 0.5302 & 0 & 0.1222 & 6.0355 & 2.5621 & 0.067 & 7.3679 \\
\hline 385 & 0.7095 & 0 & 0.1177 & 6.7955 & 1.8237 & 1.273 & 7.8373 \\
\hline 402 & 1.0921 & 0.0037 & 0.1162 & 8.6515 & 1.2981 & & 3.3431 \\
\hline 418 & 1.6571 & 0.0090 & 0.1278 & 11.7805 & 0.9426 & & 2.1505 \\
\hline 432 & 4.0425 & 0.0148 & 0.1370 & 23.7608 & 0.7124 & & 1.0319 \\
\hline 447 & 8.1192 & 0.1268 & 0.2941 & 48.7261 & 0.5278 & & 0.4881 \\
\hline
\end{tabular}




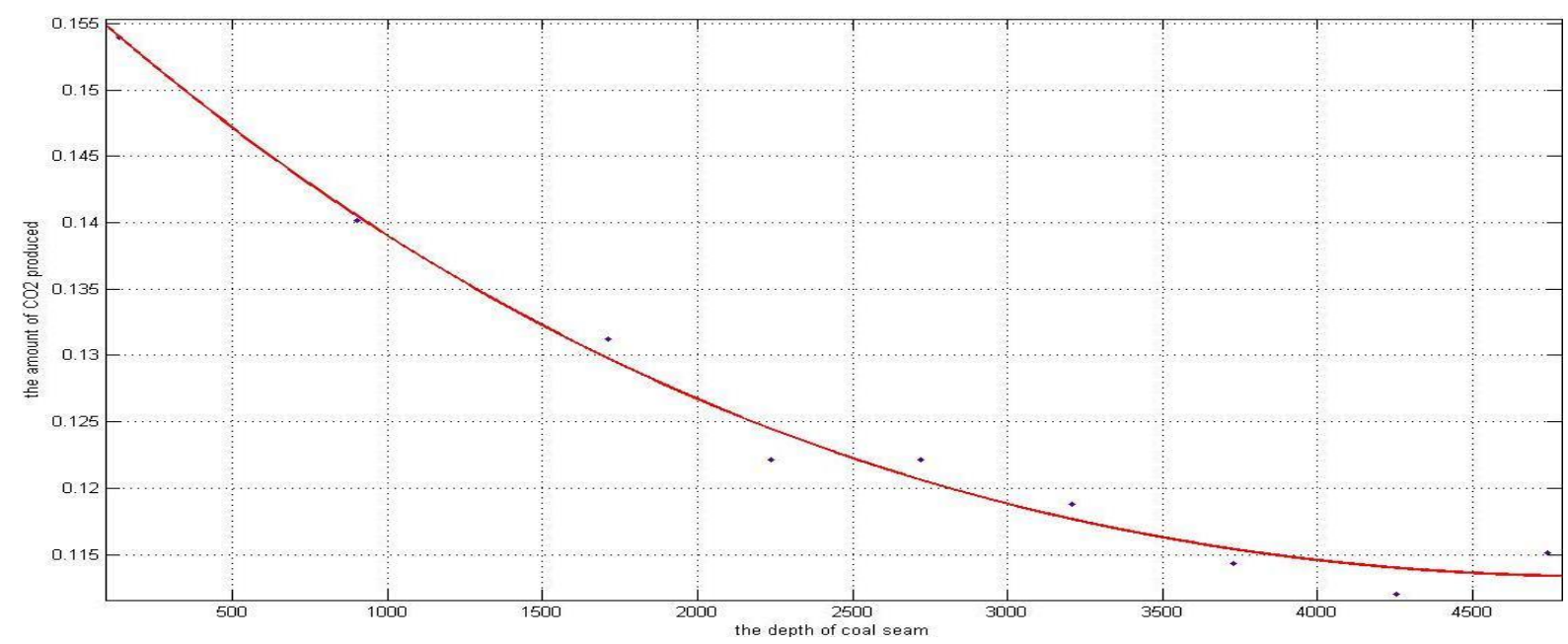

Figure 1. The curve of depth of coal seam and the amount of $\mathrm{CO}_{2}$ produced

Based on the data above, the curve about coal seam depth and the amount of $\mathrm{CO}_{2}$ produced is shown in Figure 1:

Based on the data above, the curve about coal seam depth and the amount of $\mathrm{CO}_{2}$ produced, shown in Figure 1:

As is shown in the figure 1, the curve fitted exponential function expression. The curve can be obtained as the following formula (2):

$f(x)=0.1046 * \exp (-0.000246 * x)+0.05221 * \exp (0.00009217 * x)(2)$

As from Figure 1, the greater the depth of the coal seam,

$$
\tau=\sum_{i=1}^{n} \frac{\left(C_{P}^{i}+C_{P}^{i+1}\right) \cdot\left(t_{i+1}-t_{i}\right) / 2+\Delta W_{P} \cdot \lambda / 100+\Delta \mu_{P} \cdot Q^{\prime}}{1440 \cdot\left[q\left(t_{i}\right)+q\left(t_{i+1}\right)\right] / 2}
$$

In formula (3):

$$
q(t)=n_{a}^{o}\left[\left(f_{o_{2}}\right)(t)-n_{c o}(t)-n_{c o_{2}}(t)\right]+n_{c o}(t)\left[h_{c o}^{0}(298)+\Delta h_{c o}^{0}\right]+n_{c o_{2}}(t)\left[h_{c o_{2}}^{0}(298)+\Delta h_{c o_{2}}^{0}\right]
$$

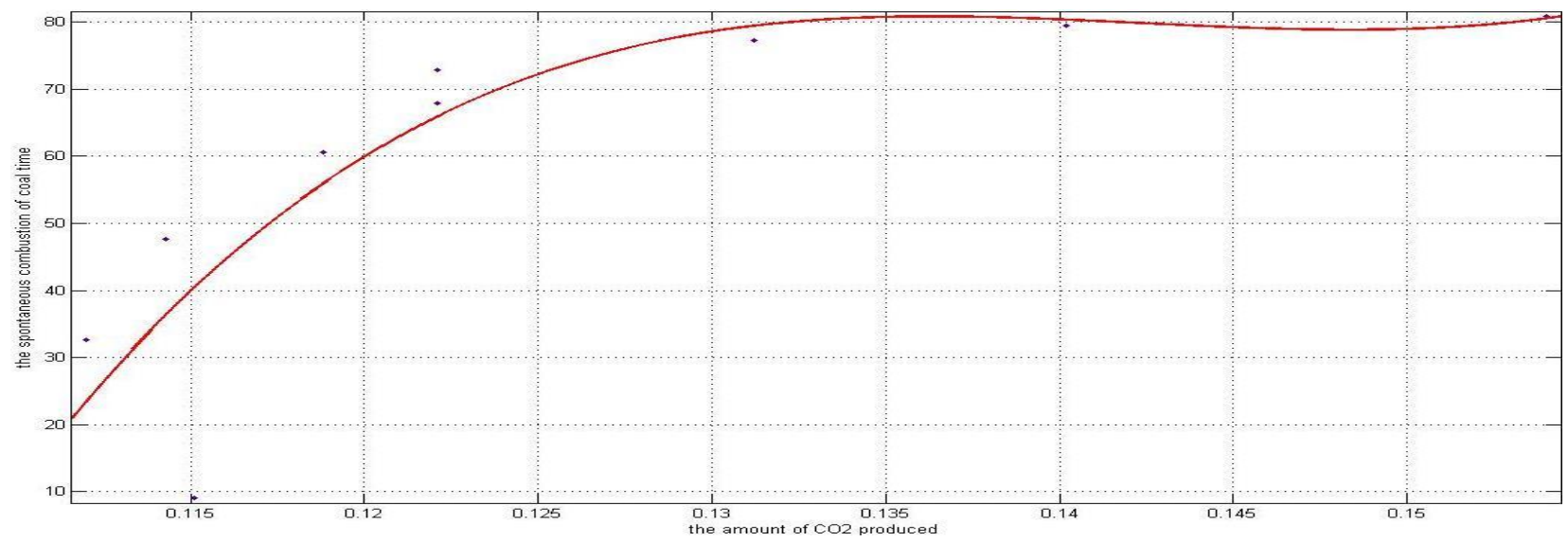

Figure 2. The curve on the spontaneous combustion of coal time and the amount of $\mathrm{CO}_{2}$ produced 
Among them, is the $\mathrm{CO}_{2}$ production rate on given conditions, unit of mol / $(\mathrm{Kg} \cdot \mathrm{min})$. It can be seen above,the amount of $\mathrm{CO}_{2}$ produced can form a direct impact on the coal spontaneous combustion period. So, in order to further explore the relationship between the amount of $\mathrm{CO}_{2}$ produced and the spontaneous combustion period of coal seam, the curve has been obtained in Figure 2 below:

It could be seen from the figure 2 , the curve is obtained as the cubic polynomial function. It is as the following

$$
f(x)=0.000002283 * x 3-0.00009752 * x 2+0.00001386 * x-647(4)
$$

It can be seen that the spontaneous combustion of coal has a process of rapid growth while the amount of $\mathrm{CO}_{2}$ change from $0.115 \mathrm{~mol} /(\mathrm{Kg} \cdot \mathrm{min})$ to $0.13 \mathrm{~mol} /(\mathrm{Kg} \cdot$ min). It is indicates that low concentrations of the $\mathrm{CO}_{2}$ gas can greatly promote their spontaneous combustion. Once the $\mathrm{CO}_{2}$ produced exceeds $0.13 \mathrm{~mol} /(\mathrm{Kg} \cdot \mathrm{min})$, the slope of the curve gentle at this stage.It is nearly approximates a straight line. This shows that when $\mathrm{CO}_{2}$ produced exceeds $0.13 \mathrm{~mol} /(\mathrm{Kg} \cdot \mathrm{min})$, the period of spontaneous combustion on the coal seam has basically no change. The process of spontaneous combustion is not sensitive in change of the amount of $\mathrm{CO}_{2}$. This regular pattern should be pay more attention to.

From the Figure 1, it can be seen that the amount of $\mathrm{CO}_{2}$ is in $0.13 \mathrm{~mol} /(\mathrm{Kg} \cdot \mathrm{min})$ or less when the coal seam depth is no exceed $1500 \mathrm{~m}$ underground. The engineering practice verifies this. This can also provides a reference for the future mining when it is depth over 1500 meters of the mine.

\section{CONCLUSIONS}

On the basis of research, the law of $\mathrm{CO}_{2}$ produced in the 13th coal seam mine and the relationship between the amount of $\mathrm{CO}_{2}$ and the spontaneous combustion period has been studied in this article. The conclusions as follows:

(1) When the mining depth of the 13th coal seam is above the level of 1000 meters underground in Sun-Cun Coal Mine, it is showed a certain linear relationship between temperature and depth.

(2) In the 13th coal seam, the law of the mine depth and the amount of the $\mathrm{CO}_{2}$ produced is with the form of exponential function.

(3) With mine depth increases after $1500 \mathrm{~m}$, the decline rate of the amount of $\mathrm{CO}_{2}$ produced has a slowed trend and the curve of spontaneous combustion period and the amount of $\mathrm{CO}_{2}$ produced in the 13th coal seam is in the form of cubic polynomial function.

(4) When the amount of $\mathrm{CO}_{2}$ produced exceed 0.13 $\mathrm{mol} /(\mathrm{Kg} \cdot \mathrm{min})$, the coal seam spontaneous combustion period basically did not change and this conclusion should be pay more attention.

\section{REFERENCES}

[1] Lang Qingtian, Sun Chunjiang, Di Jianyou, Du Jiping. Deep coal mining technology [DB / OL]. China University of Mining and Technology Press.2006.

[2] Wen Hu. The experiment and numerical simulation study in the process of Coal Spontaneous Combustion [D].Xi'an university of science and technology. 2003,5.

[3] Yu Minggao, Huang Zhicong, Yue Chaoping. A mathematical model for calculating the shortest spontaneous combustion period of coal [J]. Journal of China Coal Society. 2001.

[4] Chen Liwen. Research on the identification of coal seam spontaneous combustion risk. COAL ENGINEERG, 1992(5):48-57.

[5] Wang Shengshen, Zhang Guoshu. Mine fire prevention and control [M]. China University of Mining and Technology Press. 1999.

[6] Deng Jun, Xu Jingcai, Chen Xiaokun. Research progress of coal spontaneous combustion mechanism and prediction theory $[\mathrm{J}]$. Journal of Liaoning Technical University. 2003,22(4).

[7] Lv Zhaoshuang. The discussion about the coal spontaneous combustion mechanism [J].Safety In Coal Mines, 1994,9(9).

[8] Li Zenghua. Free radical reaction mechanism of coal spontaneous combustion $[\mathrm{J}]$. Journal of China University of Mining \& Technology. 1996,25(3):111-114. 